eISSN: 2172-9077

https://doi.org/10.14201/fjc2019182540

\title{
EL CINE DOCUMENTAL HECHO POR MUJERES COMO \\ INSTRUMENTO DE DENUNCIA Y VISIBILIZACIÓN DE LOS \\ FEMINICIDIOS SEXUALES Y LAS DESAPARICIONES DE MUJERES EN CiUdAd JuÁrez (MÉXICO)
}

\section{Documentary films made by women as an instrument for the denunciationa nd visibilization of sexual feminicides and the disappearance of women in Ciudad Juárez (Mexico)}

\author{
Dr. Javier JUÁREZ \\ Profesor a tiempo completo \\ Facultad de Comunicación de la Universidad de Medellín, Colombia. Grupo GRECO \\ E-mail: jjuarez@udem.edu.co \\ iD http://orcid.org/0000-0001-9441-8229
}

Fecha de recepción del artículo: 30/03/2019

Fecha de aceptación definitiva: 20/04/2019

\begin{abstract}
RESUMEN
El artículo analiza el cine documental elaborado por mujeres cineastas sobre los capítulos de feminicidios sexuales sistemáticos y desapariciones de mujeres en Ciudad Juárez (México) que comienzan a ser documentados y denunciados a partir de 1993 y que siguen presentes hasta la fecha. A través del estudio de dos de los principales trabajos desarrollados por mujeres cineastas sobre esta problemática se aborda la capacidad transformadora y de denuncia del cine documental, aplicando de forma transversal la perspectiva de género en su análisis.

La investigación reflexiona sobre el papel del cine documental a la hora de denunciar los abusos de poder y negligencias tan flagrantes como las detectadas en los crímenes misóginos de la frontera norte de México desde una doble lectura: La representación de la mujer en la sociedad mexicana y el papel de la mujer tras la cámara para romper la mirada androcentrista dominante.
\end{abstract}

Palabras clave: patriarcado; feminicidio; Ciudad Juárez; cine documental; información.

\begin{abstract}
The article analyzes documentary films made by female filmmakers about the episodes of systematic sexual femicides and disappearances of women in Ciudad Juárez (Mexico). Through the study of the main works developed by female filmmakers, the transformative and denouncing capacity of documentary film is addressed, applying the gender perspective in its analysis in a transversal way.

This research reflects on the role of documentary films when it comes to addressing abuses of power and negligence as flagrant as those detected in the misogynist crimes
\end{abstract}


of the northern border of Mexico from a double reading: The representation of women in Mexican society and the role of the woman behind the camera to break the dominant androcentric gaze.

Key words: patriarchy; femicide; Ciudad Juarez; media; documentary cinema; information.

\section{INTRODUCCIÓN}

Ciudad Juárez es la urbe más poblada del Estado de Chihuahua (México) y se encuentra ubicada en la frontera norte del país, frente a El Paso (Texas- EEUU). Juárez se ha consolidado en las últimas décadas como uno de los principales motores económicos e industriales de la República de México, centrando su economía a lo largo de las últimas cinco décadas en la potenciación de la industria maquiladora, nutrida, mayoritariamente, por mano de obra femenina, sometida a unas condiciones laborales deplorables marcadas por el acoso sexual y sicológico (Sánchez, 2007). Otro de los factores determinantes para entender y contextualizar la realidad socio-cultural de Ciudad Juárez es su condición de ciudad-frontera. Sus peculiaridades geográficas la han situado históricamente como un espacio estratégico para el tráfico de personas, armas y estupefacientes y, consecuentemente, como zona en disputa cuasi permanente de las estructuras del crimen organizado, siendo una ciudad marcada por una violencia endémica agudizada en determinadas etapas por la inestabilidad en los liderazgos de estas bandas criminales y las guerras abiertas entre los diferentes cárteles y sus brazos armados (Washington, 2005).

Nos situamos ante una ciudad que ha sido y sigue siendo foco de atracción de personas migrantes, contando con una cantidad de población flotante incontrolable, lo que la convierte en una urbe de tránsito en la que se calcula que más de la mitad de su población está compuesta por personas foráneas que llegaron a la ciudad fronteriza en busca de trabajo, o un futuro mejor. Debemos entender este contexto histórico y socio-cultural, idóneo para la comisión de delitos, en el marco de un proceso de consolidación progresiva de una pobreza extrema que ha servido como caldo de cultivo para reclutar personas, fundamentalmente jóvenes de bajos recursos, por parte de las estructuras delincuenciales ligadas a Los Aztecas, brazo armado del Cártel de Juárez, fenómeno que se agudizó a partir del año 2008 con el incremento de la inseguridad y la violencia sufrido en la frontera norte mexicana (Bueno, 2016), lo que se tradujo, a su vez, en un auge de los episodios de feminicidios y desapariciones de niñas y mujeres.

Ciudad Juárez ejemplifica la consolidación y los efectos devastadores de una sociedad machista, agresiva y hostil hacia las mujeres. Es en este contexto de pobreza e impunidad donde, a partir de 1993, en pleno proceso de expansión económica e industrial de la ciudad, comienzan a denunciarse los primeros casos de feminicidios sexuales seriales. Activistas e investigadoras, entre ellas Diana Rusell o Jane Caputi (Bullen, 2008), y más tarde Marcela Lagarde, tratarán de conceptualizar estos crímenes contra mujeres con el término feminicidio, el cual englobará el conjunto de violaciones a los derechos humanos de las mujeres, y que derivará, a lo largo de los años, en lo que Rita Laura Segato calificará como un femigenocidio (Segato, 2017).

Gracias al trabajo de periodistas, cineastas y activistas (muchas veces madres o hermanas de las propias víctimas) se visibilizará una realidad oculta hasta entonces que incluye las desapariciones sistemáticas de mujeres, cuyos restos serán encontrados 
días o semanas más tarde con numerosos signos de tortura y agresiones sexuales múltiples (Monárrez, 2010). La repetición del modus operandi por parte de los secuestradores y asesinos, además de las semejanzas entre las víctimas, alertará a periodistas e investigadoras que, sobre todo a partir de 1995, cuestionarán las argumentaciones oficiales, encaminadas a la minimización de los crímenes y la culpabilización de las víctimas y sus familias mediante un argumentario estructurado que perseguirá la normalización de la violencia contra las mujeres y, consecuentemente, la impunidad de estos casos.

Ciudad Juárez se ha convertido con el paso de los años en un modelo paradigmático de la permisividad gubernamental y su nulo interés en esclarecer y erradicar estos hechos. Los feminicidios sexuales de Ciudad Juárez ejemplifican la existencia de toda una estructura que permite y garantiza la impunidad sobre los casos denunciados. Es toda una cadena de pactos desde los ámbitos social, político, judicial y policial que sustenta la ideología patriarcal. Un sistema que a su vez se ve potenciado a través de la misoginia y la violencia sexual contra las mujeres y cuya «expresión máxima es el asesinato de la mujer, con el cual se produce una estrategia de mantenimiento del control [...] la violencia contra las mujeres es producto de pactos patriarcales» (Ravelo, 2008, pp. 1-2)

El Estado no sólo no ha puesto en todos estos años entre sus prioridades la erradicación de la violencia machista en sus múltiples expresiones, ni el avance en la impartición de justicia, sino que ha sido parte central de la problemática por su actitud. Celia Amorós (1994) introduce un nuevo componente a la hora de estudiar la violencia extrema contra las mujeres dentro del sistema patriarcal y la respuesta del Estado, protegiendo la cadena de complicidades y negligencias existente tras los hechos denunciados. Amorós señala en este sentido que existen "pactos entre hombres" (Amorós, 1994, p. 27) que deben ser englobados dentro de «una especie de pacto interclasista, metaestable, por el cual se constituye en patrimonio del genérico de los varones en cuanto se auto-instituyen como sujetos del contrato social ante las mujeres -que son en principio las pactadas-» (Amorós, 1994, p. 27). Las autoridades, históricamente representantes de una cultura patriarcal y misógina hegemónica, han formado y forman parte de esos pactos entre varones citados por la autora. Tal y como explica la experta en antropología Silvia Giletti (2014) en su trabajo 'Los crímenes de género y sus huellas: Aproximación al femigenocidio', han sido numerosas las estrategias llevadas a cabo por estos círculos de poder para "transmitir una versión del fenómeno que induce a considerar el crimen como una aparente normalidad” argumentando que «las víctimas serían entonces prostitutas, mujeres infieles, drogadictas, queridas de narcotraficantes, y no como en la mayoría de los casos, trabajadoras de las maquilas, empleadas, camareras, estudiantes, niñas» (Giletti, 2014, pp. 3-4). A pesar de los esfuerzos de las propias familias por visibilizar esta realidad y denunciar las negligencias y complicidades gubernamentales, la violencia estructural contra niñas y mujeres en Ciudad Juárez no ha desaparecido.

A partir del año 1995, y muy especialmente a partir de 1999, numerosos periodistas y cineastas comenzarán a cuestionar abiertamente la labor de las autoridades y a visibilizar, a través de sus trabajos, las notables y graves negligencias y redes de complicidades existentes tras estos feminicidios. En el caso del periodismo escrito, autores como Sergio González ('Reforma') Diana Washington ('El Paso Times') o Rosa Isela Pérez ('Norte de Ciudad Juárez') desarrollarán importantes contribuciones con una notable carga de denuncia, lo que les costará amenazas en unos casos, agresiones 
en otros o la expulsión de su puesto de trabajo. Por su parte, el cine documental en relación a esta problemática tiene múltiples lecturas y representaciones, pero es necesario destacar la implicación y la calidad de dos documentales como Señorita Extraviada (2001) o Bajo Juárez. La ciudad devorando a sus hijas (2006) los cuales se han consolidado como referentes internacionales del género de denuncia y que abordan la problemática social de Juárez, logrando "que existiera» esta realidad silenciada durante años. Ambos trabajos suponen una apuesta por un cine documental comprometido, activista y militante, a través del cual se da forma y voz a la representación de la mujer y aporta, además, una mirada de mujer no androcéntrica tras la cámara.

\section{OBjetivos y METOdología}

La presente investigación tiene como objetivo principal analizar los trabajos desarrollados por mujeres cineastas para, a su vez, estudiar la capacidad transformadora y de denuncia del cine documental, en este caso focalizando el campo de análisis en los feminicidios sexuales y desapariciones de mujeres documentados en Ciudad Juárez a partir del año 1993. La investigación aplica de forma transversal la perspectiva de género en su análisis y profundiza sobre aspectos ligados a la finalidad del cine documental y sus diferentes perspectivas a la hora de abordar asuntos relacionados con los abusos de poder y/o negligencias tan flagrantes como las detectadas en los crímenes misóginos de la frontera norte de México y lo hace desde una doble lectura: por un lado el análisis de la representación de la mujer en la sociedad mexicana desde una óptica plural y completa, y por otro, estudiando las aportaciones y el papel de la mujer tras la cámara para romper la mirada androcentrista dominante.

Los capítulos de feminicidios y desapariciones de mujeres y niñas en Ciudad Juárez (México) requieren un análisis contextualizado, completo y plural que ayude a enmarcar estos crímenes en el seno de una sociedad patriarcal legitimadora de la violencia feminicida y, por supuesto, huyendo de prácticas amarillistas y miradas androcéntricas y sexistas, tan comunes a lo largo de los últimos años. Para ello, el trabajo apuesta por distintos métodos de investigación cuanti-cualitativos para la consecución de los objetivos marcados y optimizar los resultados y la calidad investigativa aportando datos y reflexiones novedosas. Para ello, se llevó a cabo una revisión metódica de los principales trabajos audiovisuales desarrollados por mujeres cineastas sobre esta temática y que apuestan por una mirada crítica, por un cine documental de denuncia que, sin perder la objetividad, consigue y aporta un análisis profundo y sistemático. En este sentido, fueron seleccionados los trabajos Señorita Extraviada (Lourdes Portillo, 2001) y Bajo Juárez. La ciudad devorando a sus hijas (Alejandra Sánchez, 2006), los cuales se han convertido en referentes internacionales necesarios a la hora de entender y analizar estos capítulos desde el sector audiovisual y como ejemplos de un cine documental de denuncia efectivo.

La perspectiva cualitativa ha sido fundamental en nuestro trabajo analítico, enfocado en el estudio de los diferentes argumentos aportados por las autoridades mexicanas y haciéndolo, además, bajo un análisis histórico previo y una contextualización que ayude a entender los hechos estudiados. En este sentido, el trabajo examina los testimonios incluidos en ambos documentales, las imágenes seleccionadas y los guiones establecidos de ambos corpus para estudiar, en su conjunto, la representación de las mujeres. Para ello, contamos con aportaciones metodológicas desarrolladas 
en las obras de autores como Gutiérrez San Miguel (2006), Aumont y Marie (1990), Cerdán Los Arcos (2015) que, si bien no abordan el formato documental de manera específica -centrados en la ficción mayoritariamente-, analizan la obra desde una perspectiva integral. Esta estrategia se ve complementada por la sistematización de las cuestiones prospectivas propuestas por Alejandro Montiel (2002, p. 34) relativas a la estructuración de la obra audiovisual, como son «el análisis de la imagen y el sonido o de la representación fílmica y el análisis del relato [y] de sus estructuras narrativas». Por último, complementamos este enfoque con un encaje teórico en la línea de los Estudios Culturales (Grossberg, 2010) en cuanto a la necesidad de reflexionar, a través del documental "sobre la sociedad y trata[r] de buscar ciertas respuestas sobre problemas éticos en la sociedad actual» (Dufuur, 2010, p. 336), pues «el fundamento de la narrativa cinematográfica está en dar a conocer situaciones humanas» (MartínezSalanova, 2010, p. 48), tanto en el plano de la ficción como del documental, donde «el compromiso del autor con la verdad adquiere una relevancia determinante» (Sánchez Zapatero, 2010, p. 16-17).

Junto a ello, se desarrolla un análisis comparativo para el contraste de datos, personajes y roles, además de la observación participante en Ciudad Juárez (donde estuvimos presencialmente en reiteradas ocasiones entre 2008 y 2016) y la realización de entrevistas personales, incluyendo a una de las dos directoras, en este caso Alejandra Sánchez, buscando en todo momento potenciar la rigurosidad científica. Paralelamente, hemos recurrido al empleo de métodos cuantitativos de investigación para verificar desde una perspectiva de género la representación y el papel de la mujer en ambos documentales, así como sus roles y papeles dentro de las cintas seleccionadas.

\section{Desarrollo De la inVESTigación}

\subsection{Investigación y objetividad en los casos de feminicidios sexuales de Ciudad Juárez}

Desarrollar una labor investigativa en Ciudad Juárez en torno a los capítulos de feminicidios sexuales sistemáticos que vienen documentándose desde 1993 hasta la fecha no es una labor sencilla, ni desde el punto vista del análisis y la comprensión de su complejo contexto histórico-cultural, ni desde el punto de vista documental ya que, como señalan algunos investigadores que han ahondado en estos capítulos, adentrarse en una investigación acerca de estos hechos conlleva enfrentarse a los intereses y los pactos férreos existentes entre círculos de poder interesados en mantener y perpetuar la impunidad y el silencio que rodean a estos crímenes (Ravelo 2008, pp. 1-2). En este sentido, las amenazas, las agresiones e incluso los asesinatos de quienes han desarrollado labores de investigación y de denuncia han sido respuesta habitual en Ciudad Juárez, especialmente de activistas y/o investigadoras que se han atrevido a denunciar públicamente las numerosas negligencias y complicidades latentes. Desde el sector informativo, las amenazas o las campañas de acoso y desprestigio sufridas por mujeres que han investigado los capítulos de feminicidios sexuales y denunciado negligencias en las investigaciones han sido estrategias cuasi permanentes desde que comenzaran a denunciarse estos crímenes, sobre todo a partir del año 1995. Rosa Isela Pérez (redactora del diario 'Norte de Ciudad Juárez' y obligada a abandonar la ciudad en 2010 tras las amenazas sufridas a raíz de sus denuncias periodísticas) o Diana Washington (redactora de 'El Paso Times' y autora de 'Cosecha de mujeres: Safari en 
el desierto mexicano' (2005), víctima de una campaña de desprestigio y amenazas a raíz de sus publicaciones) personalizan la complejidad de visibilizar estos crímenes en un contexto de violencia extrema e impunidad donde se agudiza la peligrosidad, a la vez que la necesidad, de la labor periodística y de investigación.

Analizar estos hechos, o más concretamente, la forma de abordar la labor investigativa ha sido y es aún hoy objeto de un profundo debate que va más allá del periodismo en sí y que abarca, además, áreas como el cine documental, también presente y con un papel importante a la hora de abordar los casos de feminicidios sistemáticos de niñas y mujeres en Ciudad Juárez. En este sentido, como señalan Berta García Arosa y Santiago Gallur (2012), algunos investigadores han apostado por la neutralidad ante los hechos, manteniendo una postura equidistante entre víctima y victimario, buscando una supuesta objetividad, sin tener en cuenta un hecho diferencial como es que «esta situación de conflicto presenta peculiaridades que influyen especialmente en la construcción de la realidad” (Gallur y García, 2012, p. 492). Una equidistancia que, supuestamente, busca una pretendida "objetividad informativa" que "puede tener un efecto perverso como de hecho ha sucedido en el caso de Ciudad Juárez, derivando en un preocupante sesgo informativo ya que provoca que conflictos estructurales» sean «explicados periodísticamente como si fueran meros conflictos coyunturales [...] por lo tanto hay un sesgo de la realidad al ofrecernos únicamente una pequeña parte de la misma» (Gallur y García, 2012, p. 504)

El sesgo distorsionador, referido a «las noticias que distorsionan deliberadamente la realidad» (Castells 2009, p. 221), choca frontalmente con el carácter investigativo que demandan unos hechos tan graves como los que analizamos. Este choque de posturas ha sido y es aún hoy objeto de estudio. En este sentido, la asunción de una determinada postura frente a los hechos que marca un enfoque concreto sigue generando un amplio debate ético sobre el compromiso y la obligación, o no, de cineastas, periodistas y/o investigadores de arrojar luz a casos de injusticia e impunidad como son los secuestros sistemáticos de adolescentes y los feminicidios sexuales seriales denunciados. Como señala el investigador colombiano Javier Darío Restrepo (2004) la ética se fundamenta en valores como el compromiso con la verdad, la responsabilidad social y la independencia. En este sentido, cabe plantearse si es ético o no dar cobertura a declaraciones falsas o manipuladas que generan confusión o desinformación entre la sociedad, como ha ocurrido durante los años investigados sin, al menos, cuestionarlas o contrastarlas, como en el caso de Ciudad Juárez, llegando incluso a culpabilizar a las víctimas de sus desapariciones, justificando sus violaciones y asesinatos con prejuicios misóginos (Monárrez, 2009) e incluso culpando a las familias de la demora de la identificación de los cuerpos.

\subsection{El cine documental hecho por mujeres y sobre mujeres en Ciudad Juárez: Lourdes Portillo y Alejandra Sánchez}

Los trabajos desarrollados por colectivos de mujeres y activistas evidenciarán que muchas de las víctimas fueron secuestradas bien en la zona centro, bien cuando se disponían a entrar o salir de sus trabajos en la maquiladora. Este perfil de las víctimas se mantendrá principalmente entre los años 1993 y 2007, cambiando paulatina y cualitativamente a partir de 2008, donde las edades de las potenciales víctimas descienden hasta los 12 o 13 años y no se centra ya únicamente en trabajadoras de la industria 
maquiladora, sino que se amplía a estudiantes de secundaria y adolescentes que buscan trabajo en la zona centro de la ciudad.

La escasa profundización de las informaciones, apostando por un «tratamiento poco adecuado» de las mismas, provocaron el fortalecimiento de estereotipos sexistas, la «victimización de la mujer», así como la "culpabilización de las agredidas", potenciando "un efecto narcótico [...] es decir, de desensibilización» (Menéndez 2010, pp. 46-47) de la sociedad, que será una constante a lo largo de los últimos 25 años. A su vez, la reproducción de mensajes desinformativos lanzados por las Autoridades que, una vez más, buscan la culpabilización de las víctimas y la perpetuación del sistema de impunidad existente (Juárez, 2015) han favorecido la continuidad de estos crímenes.

Frente a esta realidad, el cine documental ha jugado un papel vital para luchar contra una invisibilización estratégica fortalecida desde los grupos de poder a través de un cine de denuncia que supone una apuesta decidida por superar los vicios del objetivismo formal y abordar los problemas derivados de los abusos de poder desde una óptica crítica, analítica y directa. En el caso de México, este tipo de cine documental de denuncia toma fuerza "durante las décadas de los sesenta y setenta", derivando a partir de los 80 y los 90 en dos vertientes: "por un lado, documentales de denuncia y corte periodístico", y por otro, documentales "poéticos» (Calderón, 2012, pp. 11611163). Si bien es cierto que, como señala Lauro Zavala (2012), el cine documental en México «ha ocupado un lugar marginal en las políticas de distribución y exhibición comercial» el momento actual atisba una especie de renacimiento del género en México, ya que

en la primera década del siglo XXI la tradición del documental se ha renovado no sólo con el surgimiento de condiciones de distribución y exhibición inéditas en el país sino también con la producción de materiales más próximos a la experimentación formal y con la exploración de temas igualmente inéditos (Zavala, 2012, pp. 21-28).

Aunque han sido numerosos los trabajos desarrollados desde el ámbito audiovisual, son dos los que han logrado una mayor repercusión y reconocimiento internacional por sus aportaciones y el enfoque dado a la hora de abordar la violencia misógina sistémica de Ciudad Juárez. Una de las cineastas pioneras en afrontar esta problemática, con todos los peligros y perjuicios que ello conllevaba, fue Lourdes Portillo. Su trabajo Señorita extraviada (2001) supone una apuesta por un cine documental comprometido, algo que la propia Portillo destacará, señalando que «el arte del cine puede ser utilizado al servicio de las desprotegidas", en clara referencia a su trabajo, y reivindicando abiertamente que el documental "puede adoptar una postura e informar, activar, promover el entendimiento y la compasión» (Portillo, 2003, p. 34). La obra de la directora chihuahuense ha sido premiada en varios festivales internacionales y exhibida en el extranjero y cuenta con un amplio reconocimiento, abordando la problemática sin caer en el amarillismo, sin ceder ante el tan socorrido recurso del morbo, sin necesidad de mostrar cadáveres explícitos o escenas violentas/sangrientas. La autora logra trasladar de forma amplia, seria y rigurosa la realidad, el dolor y la impunidad existente tras estos casos. Con la pluralidad y la objetividad de dar voz a todas las partes implicadas, la cineasta evidencia, entre otros asepctos, «el escenario de precarización laboral introducido por la maquila (80\% estadounidense)» (Valenzuela, 2014, p.6) y plasma de forma nítida la gravedad y los círculos de complicidad existentes tras los casos. Como señala el investigador Sergio de la Mora (2012), la artista «deja muy clara la complicidad del estado en estas atrocidades, particularmente las oficinas 
de procuración de justicia, confirma la ausencia de los derechos civiles y humanos para las mujeres en México y la urgencia de organizarse para exigir estos derechos». A través de su proyecto ético-estético, personal y afectivo, Portillo moldea «su praxis documentalista en torno a la cultura fronteriza» a través del análisis de casos particulares, aportando «una visión panorámica de la relación entre sexualidad y violencia en la zona fronteriza» (D'Lugo, 2003, p. 40).

Señorita extraviada (2001) supone un antes y un después en la visibilización de los feminicidios de Ciudad Juárez. La cineasta mexicana Lourdes Portillo aporta una mirada nítidamente femenina y feminista, haciendo visible lo invisible, implicándose, además, de forma personal desde el inicio, cuando una voz en off abre el documental señalando: «Vine a Juárez para presenciar el silencio y el misterio que rodea la muerte de cientos de mujeres» (Portillo, 2001) y profundiza en un análisis completo y plural de los hechos mediante un relato de gran validez y calidad audiovisual, dando voz a las partes implicadas, incluyendo a las autoridades, que no dudaron en afirmar que las víctimas eran "prostitutas que de alguna forma se habían buscado ese desenlace, e incluso llegaron a proponer la medida de un toque de queda para que las mujeres decentes no salieran de su hogar a horas inapropiadas» (Calderón 2012, p. 1164). Portillo da voz a sospechosos detenidos como supuestos asesinos seriales, como Abdel Shariff, fallecido durante su periplo carcelario en el que defendió en todo momento ser un chivo expiatorio. También deja espacio para la versión oficial, como la aportada por el ex gobernador Francisco Barrio, quien afirmó que «las mujeres asesinadas eran prostitutas (...) o Jorge López Molinar» (Valenzuela, 2014, p. 6).

Portillo aporta una mirada analítica feminista hasta entonces ausente y da voz a las sin nombre, aunque, como señala la investigadora Virginia Villaplana (2009), la obra «no aporta soluciones, sólo presenta los hechos y es el gobierno mexicano el que tiene que darle una solución». Su impacto internacional consiguió poner a Ciudad Juárez en el punto de mira de asociaciones y organismos internacionales a través de la implicación personal de la propia Portillo, quien hizo «un llamamiento para firmar la carta de petición al presidente de México y al gobernador de Chihuahua» con el fin de "resolver los terribles crímenes cometidos contra mujeres en Ciudad de Juárez y que ambos niveles del gobierno evaden» (Villaplana, 2009, p. 477). Su impacto fue tal, que a partir del año 2001, tomarán fuerza importantes movimientos de mujeres, como, por ejemplo, 'Nuestras Hijas de Regreso a Casa' (Ciudad Juárez) o 'Justicia para Nuestras Hijas' (Chihuahua), además de movimientos internacionales como la 'Caravana Internacional por la Justicia en Ciudad Juárez y Chihuahua', que recorrió 53 ciudades de Canadá y Estados Unidos hasta retornar a Ciudad Juárez, o apoyos de organizaciones e instituciones "como la Universidad Libre de Berlín y la Liga Internacional de Mujeres por la Paz y la Libertad» (Espeleta, 2015, pp. 1001-1002) o personajes influyentes, como actores o cantantes mundialmente conocidos que legitimaron las denuncias y las reivindicaciones de las madres de Ciudad Juárez.

Aplicando un análisis desde la óptica cuantitativa, Portillo rompe con la mirada androcéntrica dominante y apuesta por dar voz y protagonismo a ellas, las mujeres. Este hecho queda reflejado en un estudio realizado para el desarrollo del presente trabajo, donde, además de la voz en off femenina que guía la acción de la trama, se da voz a un total de 14 mujeres, de las cuales seis son víctimas directas o indirectas (familiares de víctimas) de abusos por partes de las autoridades. Junto a ellas, se reproducen los testimonios de dos activistas y una abogada crítica con la labor gubernamental, tres vecinas de Ciudad Juárez y una testigo de la que se preserva la identidad, además de 
EL CINE DOCUMENTAL HECHO POR MUJERES COMO INSTRUMENTO DE DENUNCIA...

una representante del Gobierno, la Fiscal Sully Ponce. Frente a ello, el documental recoge los testimonios de 10 personajes masculinos, de los cuales tres son familiares de mujeres asesinadas, concretamente dos padres y un hermano. Otros tres testimonios corresponden a detenidos como supuestos asesinos seriales que defienden su inocencia. Por último, también se concede espacio para actores políticos relevantes, en total tres (Francisco Barrio, Jorge López y Ramón Galindo) y un ciudadano que narra cómo localizó el cuerpo de una joven reportada como desaparecida.

\section{GRÁFICA 1}

\section{Personajes con voz en Señorita Extraviada}

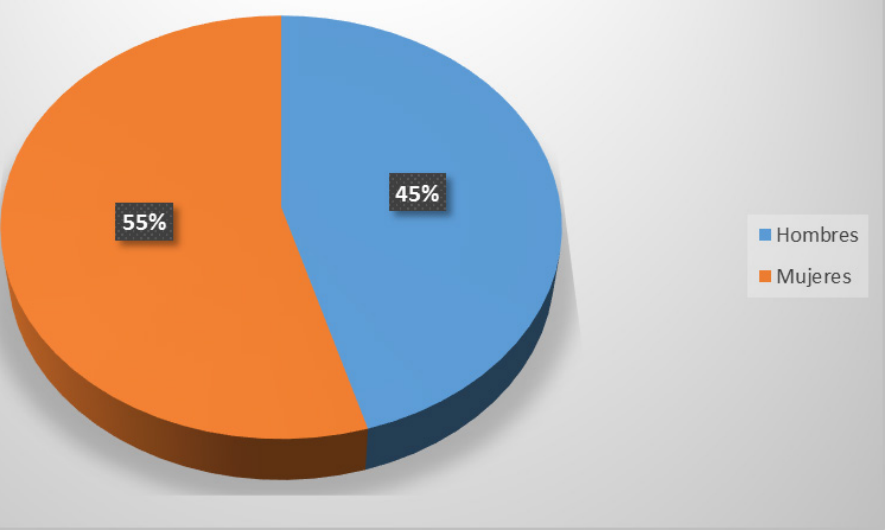

(Fuente: Elaboración propia).

GRÁFICA 2

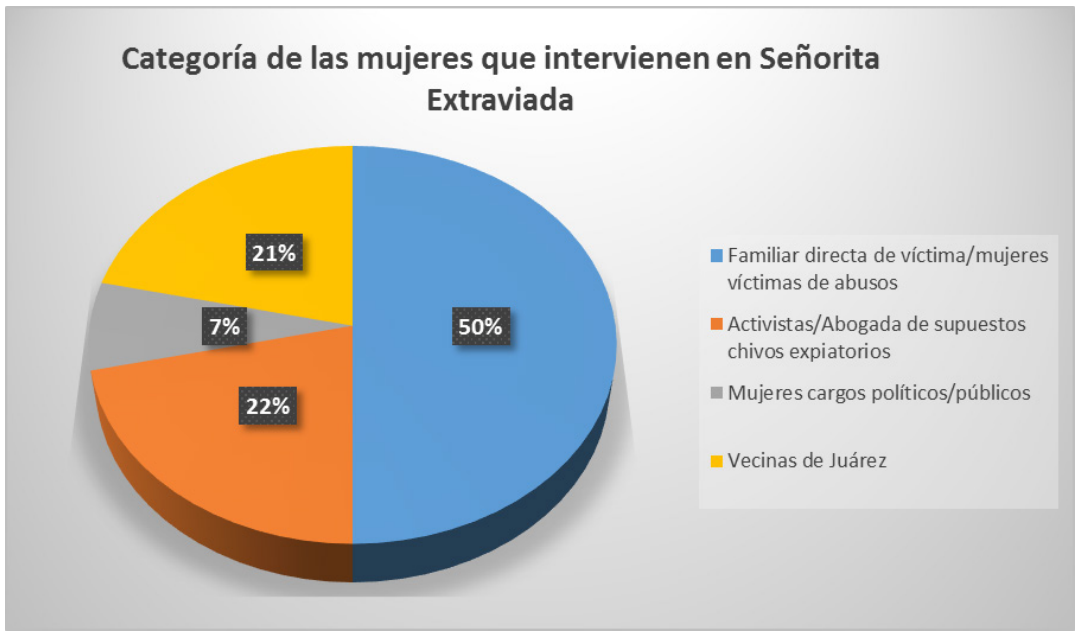

(Fuente: Elaboración propia). 


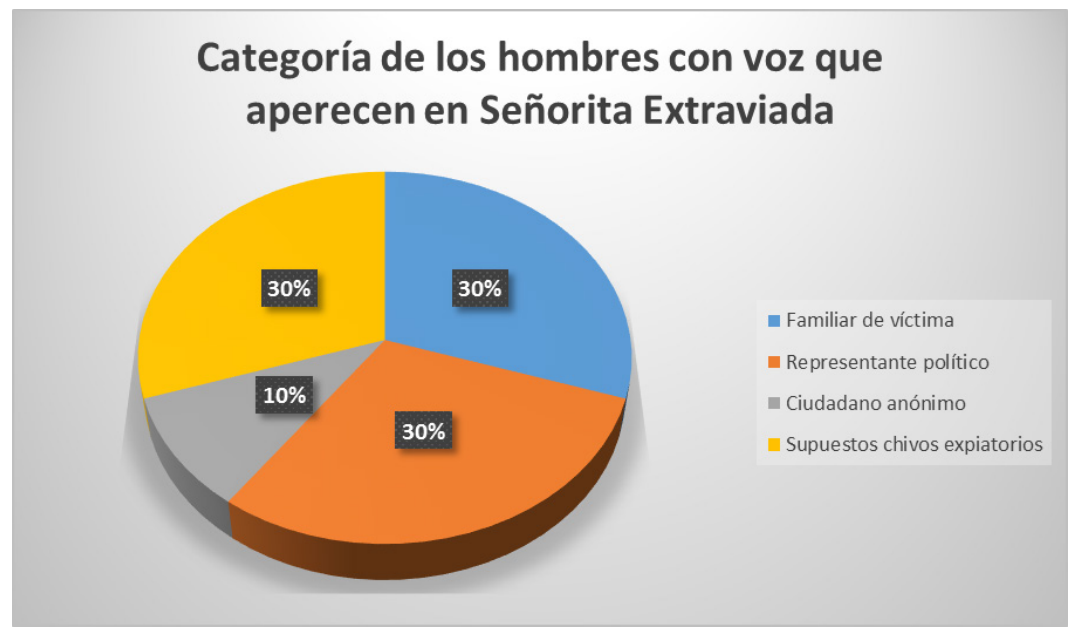

(Fuente: Elaboración propia).

El segundo de los trabajos que marcaron una apuesta por un cine documental de denuncia hecho por mujeres y sobre mujeres es Bajo Juárez. La ciudad devorando a sus hijas (2006), de la investigadora Alejandra Sánchez, quien también se implica en la denuncia y consigue una importante relevancia internacional. Años después del rodaje del documental, Sánchez denunciará respecto al papel de las autoridades que "de alguna forma decían que era parte de la normalidad y que solo les pasaba a ciertas mujeres [...] con una actitud regionalista que creo fuera de lugar» (Juárez, 2015, p. 314). Como señala la investigadora Erika Almazán (2012, p. 133) «la autora se coloca ante el problema de los feminicidios con una mirada crítica y propositiva para ayudar a solidarizarse con el sentir de la gente, con los familiares de las víctimas». Alejandra Sánchez aborda, a través del feminicidio de Lilia Alejandra Andrade (secuestrada el 14 de febrero de 2001 y localizada asesinada una semana después) la gravedad de los feminicidios sexuales de Ciudad Juárez que siguen estando presentes cinco años después del estreno de la obra de Portillo.

El documental aborda una realidad pasada y presente en Ciudad Juárez a través de hechos ya acontecidos pero que, a su vez, generan y defienden la memoria como mecanismo para reivindicar justicia. En esta ocasión, y a diferencia de Señorita extraviada (2001), la directora pasa a un plano invisible, donde es «el otro [el que] suscita la condición de narratividad» (Almazán, 2012, p. 134). Las mujeres, activistas, que llevan el peso del documental, son esa "otra [que] denuncia, que expresa, que se desahoga, que cuenta, que reclama, que exige: todo a partir de la empatía que genera en este caso el dolor de perder a una hija” (Almazán, 2012, p. 135). En este sentido es Norma Andrade, co- fundadora 'Nuestras Hijas de Regreso a Casa', quien narra su historia y «representa simbólicamente a todas las madres que han sufrido la pérdida de sus hijas, asesinadas impunemente» (Almazán, 2012, p. 137). Además, Sánchez da voz a las versiones oficiales, incluyendo entrevistas a altos cargos de las diferentes administraciones, entre ellas las Fiscales Especiales para Crímenes contra Mujeres, Sully Ponce y María López Urbina, además de a periodistas como Diana Washington o Sergio González. 
La directora y editora del documental Bajo Juárez: La ciudad devorando a sus hijas (2006) reconocerá años más tarde que tras presentar el trabajo y lograr una notable repercusión internacional:

Pasamos momentos de angustia, aunque nunca recibimos de forma directa amenazas, las evidencias de hostilidad eran de otra manera, más sutil. [...] Cuando hicimos el trabajo en Juárez nunca dijimos que éramos prensa, y eso nos permitió caminar de manera más silenciosa, más discreta, aunque una vez encontramos los cajones revueltos en el hotel, lo cual nos alertó. [...] Tras presentar la película en México e incluso a nivel internacional, yo ya no regresé a Juárez por cuestiones de seguridad. [...] Yo creo que el fenómeno responde a una maquinaria de poder en donde juegan una serie de círculos concéntricos, de complicidades entre las cúpulas de poder y las autoridades encargadas de hacer valer la Justicia. [...] es un enjambre, un círculo de complicidades en el que la mayoría de los medios locales juegan un papel en el que muchas veces desinforman, ocultan o colaboran con esta voz corrupta de las autoridades culpando a las propias víctimas [...] desde el Gobierno de Barrio, que decía que la mayoría de las víctimas eran sexoservidoras, como si eso fuera motivo para carecer de derechos y convertirte en potencial víctima de estas atrocidades, las voces que han opinado y que vienen de fuera colaboran a la demanda de justicia y el Gobierno en este sentido ha sido no sólo omiso sino cínico. [...] Yo celebré la sentencia de la Corte Interamericana del Campo Algodonero y creo que algunos periodistas de fuera junto a las madres han logrado que este fenómeno siga siendo noticia, no ya en primera plana, pero sí siendo noticia en un país que carece de Justicia y donde las tragedias se normalizan [...] los crímenes de mujeres no paran en Ciudad Juárez y eso no me lo explico de otra forma que con la existencia de un poder político y empresarial detrás y las autoridades (Juárez, 2015, p. 318).

Bajo Juárez: La ciudad devorando a sus hijas (2006), a diferencia de Señorita extraviada (2001), apuesta, en numerosas ocasiones, por la voz en off, pero en este caso de periodistas que informan sobre diversos acontecimientos relacionados con la violencia misógina. Además, recurre a una trabajadora de maquila para visibilizar el tipo de vida que afrontan las mujeres que llegan a Ciudad Juárez en busca de trabajo. Las mujeres son el centro de atención y las verdaderas protagonistas del documento, tomando una especial relevancia la figura de Norma Andrade, madre de Lilia Alejandra García Andrade, asesinada en febrero de 2001 y cuyo caso es abordado y sirve como guía para unir historias y denuncias muy similares y marcadas todas ellas por la impunidad. También a diferencia de Portillo, Sánchez sí emplea imágenes explícitas y directas sobre casos de feminicidios y localizaciones de cuerpos de mujeres en lotes baldíos y canales de aguas negras.

El trabajo personaliza la lucha de las mujeres de Juárez en la figura de la activista y madre de adolescente asesinada, Norma Andrade, y, al igual que sucediera con Portillo, no incurre en la revictimización, aunque en este caso sí pone nombre y apellidos a denuncias directas a través de las madres de las víctimas. Sánchez señala espacios donde posiblemente fueron retenidas las jóvenes durante su cautiverio y en algunas fases de la cinta aporta datos muy concretos y denuncias explícitas para evidenciar la red de mentiras y complicidades existentes.

Al igual que sucediera con Señorita extraviada (2001), el trabajo consiguió una enorme repercusión, siendo expuesto tanto en festivales internacionales como nacionales de prestigio y obteniendo reconocimientos como el de Mejor Largometraje Documental del XV Festival Iberoamericano de Cine y Vídeo de Río de Janeiro (Brasil) 
en 2008, el Premio al Mejor Documental en el Festival de Cine Contra el silencio todas las voces (México) en 2008 y en el Chicago Latino Film Festival (Illinois, Estados Unidos) en 2007 y en el Festival de Cine Latino de San Diego (Estados Unidos), también en 2007, entre otros. Su repercusión y su papel como agente de denuncia fue tal que poco después de su presentación internacional se incrementaron las amenazas y las agresiones a las activistas que formaron parte de este. Marisela Ortiz (perteneciente a la organización 'Nuestras Hijas de Regreso a Casa') se vio obligada a abandonar Ciudad Juárez en marzo de 2011 tras ser amenaza de muerte a través de una manta situada en el exterior del colegio en el que impartía clases en la que se anunciaba su asesinato. Pocos meses después, Norma Andrade sufría un atentado contra su persona, recibiendo varios impactos de bala "por un desconocido con un arma de fuego al salir de su casa en Ciudad Juárez». A pesar de salir con vida, Norma y sus nietos se vieron obligados a abandonar la ciudad.

Aplicando un análisis desde la óptica cuantitativa, observamos cómo Sánchez también rompe con la mirada androcéntrica predominante y guía su historia a través de los testimonios de las mujeres. En total, Bajo Juárez (2006) recoge los testimonios de 34 personas, de las cuales 23 son mujeres y 11 personajes masculinos. En relación a las primeras, un total de 11 son familiares de víctimas o mujeres víctimas de abusos por partes de las autoridades. Junto a ellas, se reproducen los testimonios de tres cargos públicos relevantes como son Sully Ponce, Guadalupe Morfín y López Urbina, que suponen la contraparte a las denuncias de madres y activistas y, además, se recogen los testimonios de tres mujeres familiares de supuestos chivos expiatorios. Por último, Sánchez recurre al testimonio de cuatro mujeres vecinas de Ciudad Juárez para visibilizar y entender los modelos de vida de las mujeres que habitan en Juárez, y da voz y una amplia cobertura a las reflexiones de la periodista Diana Washington ('El Paso Times'), así como de la actriz Jane Fonda, que encabezó la lucha internacional para visibilizar los feminicidios en la frontera mexicana y trabajó como legitimadora de la lucha y las reivindicaciones de las mujeres de Ciudad Juárez. Frente a ello, el documental recoge los testimonios de 11 personajes masculinos, de los cuales cuatro son periodistas (tres de ellos aparecen en voz en off), el forense municipal Óscar Maynez, un familiar de mujer asesinada, los testimonios de tres posibles chivos expiatorios varones y, por último, testimonios del entonces presidente Vicente Fox. 


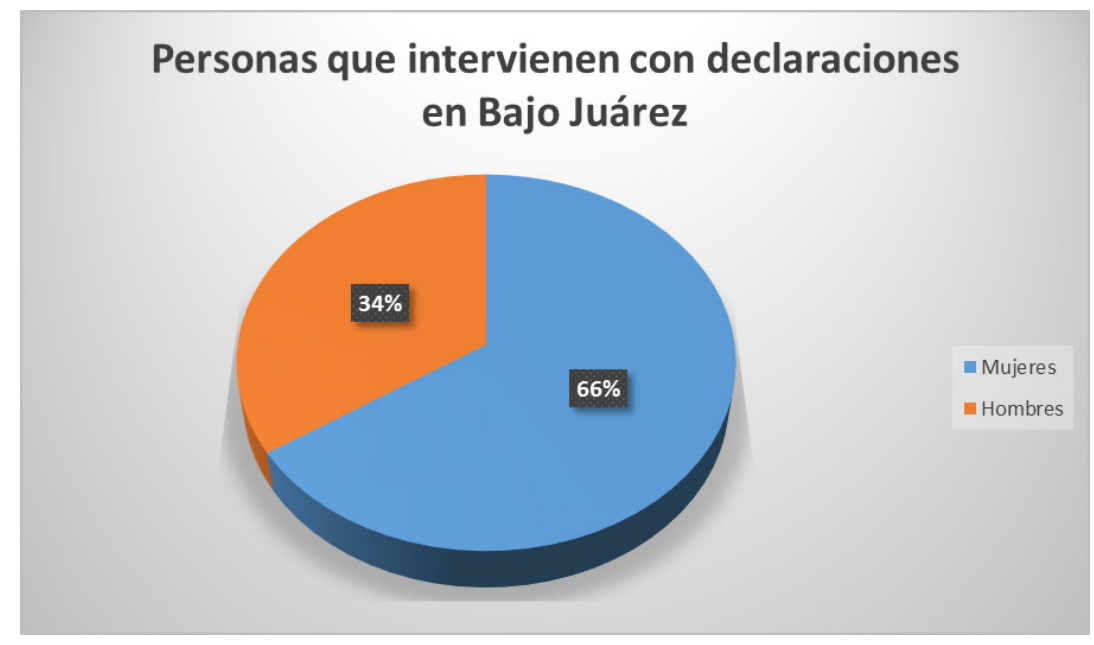

(Fuente: Elaboración propia).

\section{GRÁFICA 5}

\section{Categoría a la que pertenecen las mujeres} que participan en Bajo Juárez

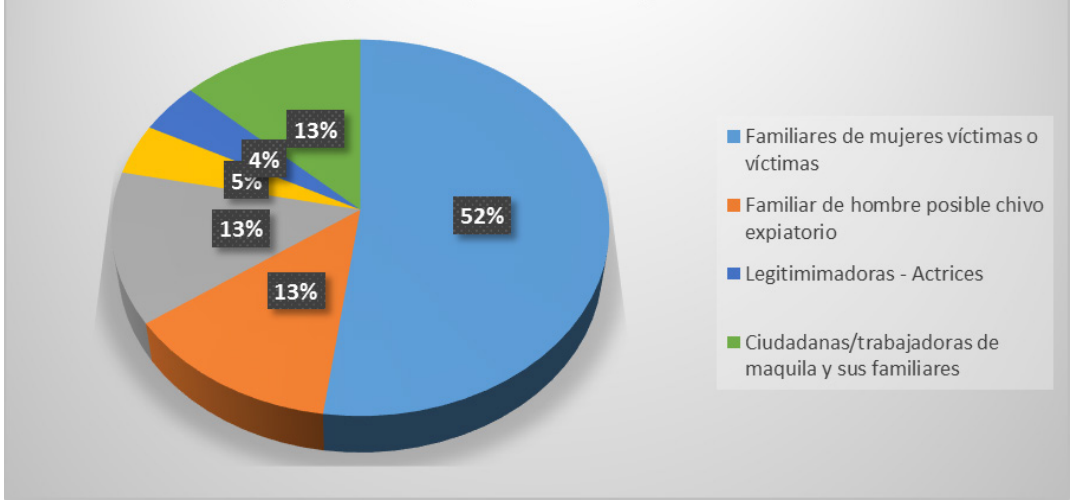

(Fuente: Elaboración propia). 


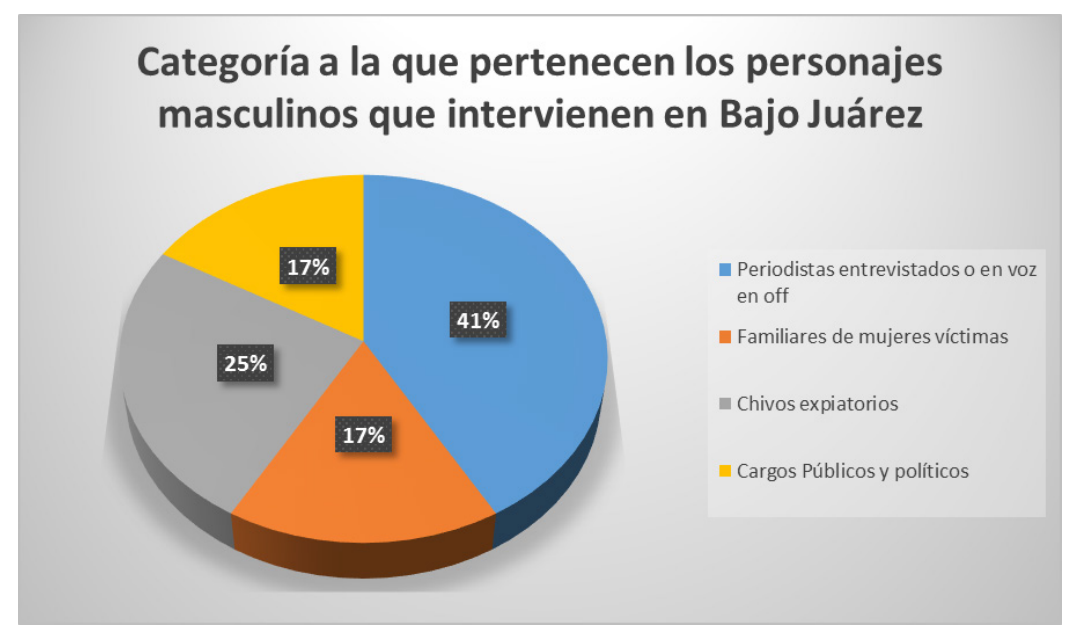

(Fuente: Elaboración propia).

\section{Conclusiones}

El cine documental ha sido a lo largo de las últimas dos décadas una herramienta fundamental a la hora de dimensionar la gravedad de los capítulos de feminicidios sexuales y desapariciones de niñas y mujeres en Ciudad Juárez documentados a partir de 1993. Aunque han sido numerosos los trabajos audiovisuales realizados alrededor de esta problemática, y desde muy diversos enfoques, dentro del cine documental destaca la relevancia y los aportes de dos trabajos enmarcados dentro del cine de denuncia, como son: Señorita Extraviada (2001) y Bajo Juárez. La Ciudad devorando a sus hijas (2006). Ambas cintas han conseguido visibilizar el grado de complejidad que engloba este fenómeno, así como la red de complicidades que subyace en los pactos patriarcales existentes en la frontera mexicana.

Tal y como planteábamos al inicio del presente artículo, los trabajos dirigidos por Lourdes Portillo y Alejandra Sánchez marcaron un antes y un después, tanto por los enfoques aplicados a sus obras como por el carácter de denuncia que guía ambas cintas. La mirada feminista de ambas directoras se plasma en una óptica nueva respecto a la gran mayoría de los trabajos precedentes, donde las mujeres pasan a ser las verdaderas protagonistas, superando la revictimización y el amarillismo y apostando por un cine documental directo, en el que ellas, las mujeres de Ciudad Juárez, pasan a ser el otro, a tener voz propia en lugar de impuesta, a tener discurso en lugar de ser discurseadas, a existir en lugar de ser silenciadas y difuminadas, todo ello desde un análisis plural y riguroso donde se da voz a todas las partes implicadas en la problemática. Aunque ambos trabajos apuestan por enfoques diferentes a la hora de abordar la problemática y que, incluso, la estrategia narrativa varía, ambas cintas se fundamentan en un cine documental comprometido con la denuncia, basado en el activismo y defensor de una óptica analítica no androcéntrica, tanto en sus protagonistas como tras las cámaras. 
Junto a ello, es de destacar como el cine documental de denuncia desarrollado por Portillo y Sánchez ha logrado, efectivamente, una importante repercusión y una indudable capacidad transformadora, como se demuestra en el presente artículo. Ambas cintas consiguieron situar a Ciudad Juárez en el punto de mira internacional y encadenar una ola de solidaridad y sororidad internacional de apoyo a las madres de las víctimas de Ciudad Juárez, sin olvidar las acciones políticas y judiciales puestas en marcha, llegando, a, incluso, elevar la problemática al Parlamento Europeo en 2007 a través de los europarlamentarios españoles Elena Valenciano y Raúl Romeva.

A pesar de los esfuerzos y los avances cosechados a lo largo de las últimas dos décadas, los feminicidios y la impunidad siguen presentes en Ciudad Juárez, por lo que se hace más necesario que nunca reivindicar la importancia y la necesidad de un cine documental de denuncia que visibilice esta realidad aún presente en la frontera norte de México, para exigir cambios estructurales y que no caiga en el olvido social e institucional; para hacer memoria y para, como hemos analizado, hacer que cientos de mujeres asesinadas o desaparecidas obtengan justicia y sus nombres, y sus historias, no pasen a ser un número más o una estadística más.

\section{Bibliografía}

Almazán, E. (2012). Acción política y medios de comunicación: de la muerte a la irrupción. Veredas, Revista del pensamiento sociológico, 24 (13), 133-150 [https://bit.ly/2V3rVjS]

Amorós, C. (1994). Feminismo: Igualdad y diferencia. Capítulo I. México. PUEG-Programa Universitario de Estudios de Género-. México DF: Universidad Nacional Autónoma de México.

Aumont, J. y Marie, M. (1990). Análisis del film. Barcelona: Paidós.

Bueno, A. (2016). Espacio público, inseguridad y violencia en Ciudad Juárez (2007-2012). En Quintana, J; Barraza, M, Herrera, R; Pineda, S. Pensar (Coord.), Pensar la Ciudad (pp. 57-79). Ciudad Juárez, México: Instituto Municipal de la Mujer.

Bullen, M. y Díez, C. (2008). Retos Teóricos y nuevas prácticas. Bilbao: Universidad del País Vasco.

Calderón, O. (2012). Hacer visible lo invisible: teoría feminista del cine y Documentales mexicanos realizados por mujeres en el siglo XXI. I Congreso Internacional de Comunicación y Género. Sevilla (España). 5-7 marzo de 2012, 1158-1170.

Castells, M. (2009). Comunicación y poder. Madrid: Alianza Editorial.

Cerdán Los Arcos, J. F. (2015). Un lugar ético para las imágenes documentales (en el /contexto de las ciencias sociales). En Fernández Guerra, V. (Ed.), Revisitando el cine documental: de Flaberty al webdoc (pp. 17-32). La Laguna (Tenerife): RLCS. [https://bit.ly/2OGUodb]

D’Lugo, M. (2003). La frontera en tres documentales de Lourdes Portillo. Secuencias: Revista de bistoria del cine, 18, 73-83. [https://bit.ly/2OCZAyI]

Dufuur, L. (2010). Tendencias actuales del cine documental, FRAME, 6, 312-349 [https://goo.gl/ UxHkAP]

Espeleta, M. (2015). Testimonio y subalternidad hoy en torno a dos colectivos de mujeres mexicanas en lucha. Kamchatka, 6, 989-1009. [https://bit.ly/2OA4R9X]

Gallur, S. y García, B. (2012). La conformación de valores noticia en un contexto de conflicto. Análisis pragmático de su funcionamiento en la información sobre narcotráfico en México y el feminicidio de Ciudad Juárez. Estudios sobre el mensaje periodístico, 18 (2), 491-511. [https://bit.ly/2Um6nlr]

García, A. (2011). Amenazan de muerte a Marisela Ortiz. Cimac Noticias. Recuperado de: https:// www.cimacnoticias.com.mx/node/40793 
Giletti, S. (2014). Los crímenes de género y sus huellas: Aproximación al femigenocidio. DEP Revista Telemática Di Studi sulla Memoria Femmminile. Número 24. Pp 1-17. [https://bit. $\mathrm{ly} / 2 \mathrm{HMsStV}]$

Gutiérrez San Miguel, B. (2006). Teoría de la narración audiovisual. Madrid: Cátedra. Signo e Imagen

Juárez, J. (2015). Estrategias y campañas de desinformación gubernamental y manipulación informativa en relación a los feminicidios y secuestros de mujeres y niñas en Ciudad Juárez entre 1993 y 2013. Tesis Doctoral. Universidad Complutense de Madrid, Madrid.

Martínez-Salanova Sánchez, E. (2010). Los sistemas educativos en la memoria heterodoxa del cine europeo. Comunicar: Revista científica iberoamericana de comunicación y educación, 35, 1134-3478.

Menéndez, M. I. (2010). Representación mediática de la violencia de género. Análisis de la prensa balear 2004/2008. Palma- Illes Balears: Ediciones UIB.

Monárrez, J. (2009). Peritaje sobre Feminicidio Sexual Sistemático en Ciudad Juárez Presentado ante la Corte Interamericana de Derechos Humanos. Santiago de Chile. Disponible en:

http://www.corteidh.or.cr/docs/casos/expedientes/Mon\%C3\%A1rrez.pdf

Monárrez, J. (2010). Las diversas representaciones del feminicidio y los asesinatos de mujeres en Ciudad Juárez, 1993- 2005. En Cervera, L; Fuentes, C; Monárrez, J; Rubio, R. (Coord.). Violencia contra las mujeres e inseguridad ciudadana en Ciudad Juárez, Vol. II. México: Miguel Ángel Porrúa Editores.

Montiel, A. (2002). El desfile y la quietud. Análisis fílmico versus Historia del Cine. Valencia: Generalitat Valenciana.

Portillo, L. (2003). Filming Señorita Extraviada. Aztlán 28 (2), 229-234.

Ravelo, P. (2008). El fenómeno del feminicidio: Una propuesta de recategorización. México DF: Centro de Investigaciones y Estudios Superiores en Antropología Social (CIESAS).

Restrepo, J. D. (2004). El zumbido y el moscardón: Taller y consultorio de ética periodística. Bogotá: Fondo de Cultura Ecnómica,

Sánchez, E. (2007). Feminicidio y maquila en Ciudad Juárez. ICEV. Revista d'Estudis de la Violencia, 2, 2-12 [https://bit.ly/2HN8rwV]

Sánchez Zapatero, J. (2010). Autobiografía y pacto autobiográfico revisión crítica de las últimas aportaciones teóricas en la bibliografía científica hispánica. Ogigia: Revista electrónica de estudios hispánicos, 7, 5-17 [https://goo.gl/M2NJdB]

Valenzuela, J. M. (2014). Ciudad Juárez: La frontera más bonita. Alternativas, 3, 1-16. [https:// bit.ly/2uBLzbc]

Villaplana. V. (2009) Formas de violencia globalizadas: género, representación y discurso. I/C - Revista Científica de Información y Comunicación, 6, 463-482. [https://bit.ly/2Um8GF6]

Washington, D. (2005). Cosecha de Mujeres: Safari en el desierto mexicano. Barcelona: Océano.

Zavala, L. (2012). El nuevo documental mexicano y las fronteras de la representación. Revista TOMA UNO, 1, 25-36. [https://bit.ly/2OwSI5R] 